\title{
Contribution of genetic factors other than CFTR to disease severity in cystic fibrosis
}

\author{
Jeremy Hull, Anne H Thomson
}

\begin{abstract}
Background-Disease severity in patients with cystic fibrosis shows marked variability. Attempts to explain this phenotypic heterogeneity on the basis of CFTR genotype have had limited success. A study was undertaken to test the hypothesis that naturally occurring variants of the pro-inflammatory cytokine tumour necrosis factor alpha (TNF- $\alpha$ ) and the detoxifying enzyme glutathione S-transferase M1 (GSTM1) could influence disease severity in cystic fibrosis.

Methods-Fifty three children with cystic fibrosis were studied. To allow for the effect of age, all clinical details were collected during the eighth year of age. The subjects were divided into groups, both according to the presence or absence of the TNF2 TNF- $\alpha-308$ promoter polymorphism $(n=20)$, and by homozygosity for the null allele of GSTM1 $(n=26)$.

Results-Percentage predicted forced expiratory volume in one second $\left(\mathrm{FEV}_{1}\right)$ and weight $z$ scores were significantly lower in the TNF2 group (mean difference $(95 \%$ confidence intervals) for FEV $11.6 \%(1.7$ to 21.5$)$ and $0.59(0.06$ to 1.12$)$ for weight $z$ score). The Chrispin-Norman chest radiographic score was significantly higher and the Shwachman score was significantly lower in patients homozygous for the GSTM1 null allele.

Conclusions-Two independent genetic factors have been identified which appear to influence disease severity in cystic fibrosis. These results support the contention that inflammation in cystic fibrosis contributes to tissue damage. Isolation of further such factors may lead to identification of patients at risk of more severe disease and allow targeted aggressive therapy in this group.

(Thorax 1998;53:1018-1021)
\end{abstract}

Department of

Paediatrics, John

Radcliffe Hospital,

Headington, Oxford

OX3 9DU, UK

J Hull

A H Thomson

Correspondence to: Dr J Hull.

Received 2 April 1998

Returned to author

6 July 1998

Revised manuscript received

21 July 1998

Accepted for publication

17 August 1998
Keywords: cystic fibrosis; disease severity; genetic modifiers

Cystic fibrosis is the most severe autosomal recessive disease in Caucasian populations and affects nearly 7000 people in the UK. The disease is characterised by pancreatic dysfunction and progressive endobronchial inflammation and infection. The median life expectancy is now approximately 30 years. There is, however, considerable heterogeneity in disease severity between different individuals with cystic fibrosis. Attempts to link phenotype with specific CFTR mutations have had some success, par- ticularly for pancreatic disease status. ${ }^{12}$ Nevertheless, marked disease variability amongst individuals with the same CFTR genotype, who share a similar environment and who attend the same cystic fibrosis centre, suggests the presence of other genetic elements at non-cystic fibrosis loci that can affect disease severity. Attempts have been made to identify disease modifying genes in the cystic fibrosis mouse. ${ }^{3}$ This approach is hampered by the shortcomings of the cystic fibrosis mouse as a model for the human disease, particularly the observation that gastrointestinal problems are the greatest cause of mortality in these animals. Most of the morbidity and mortality in human subjects with cystic fibrosis is as a result of lung disease. The mechanism of lung damage in cystic fibrosis is not fully understood. Pulmonary inflammation is intense, persistent, and of early onset. It seems likely that this overexuberant host inflammatory response, possibly via increased pulmonary oxidative stress $^{45}$ or increased free elastase activity ${ }^{6}$ is responsible for most of the lung damage that occurs.

Tumour necrosis factor alpha $(\mathrm{TNF}-\alpha)$ is a pro-inflammatory cytokine produced predominantly by macrophages. It is found in high concentrations in the lungs of patients with cystic fibrosis ${ }^{7}$ and is likely to be important in promoting the intense neutrophil dominated inflammation found in this disease. One study has found an inverse relationship between concentrations of TNF- $\alpha$ in the sputum of patients with cystic fibrosis and lung function. ${ }^{8}$ These observations suggest that the severity of lung disease in cystic fibrosis may be related to the genetic propensity of the host to produce TNF- $\alpha$. A polymorphism in the promoter region of the TNF- $\alpha$ gene, at nucleotide -308 relative to the transcription start site, may be important in determining the host $\mathrm{TNF}-\alpha$ response. ${ }^{10}$ There are two alleles at the polymorphic site, TNF1 and TNF2. The TNF2 allele is associated with higher constitutive and inducible levels of transcription of TNF- $\alpha$ than the TNF1 allele. ${ }^{10}{ }^{11}$ The TNF2 allele has shown a positive association with a number of disease states ${ }^{12} 13$ and has recently been found to be associated with an increased risk of developing chronic bronchitis. ${ }^{14}$

The major local pulmonary antioxidant is glutathione which is present in high concentrations in the epithelial lining fluid. Glutathione S-transferases (GST) detoxify harmful organic hydroperoxides which form as a result of exposure to oxidant stress, such as that found in the lungs of patients with cystic fibrosis, ${ }^{5}$ by conjugating them with glutathione, thereby preventing further pulmonary damage. ${ }^{15}$ One of this 
family of enzymes, GSTM1, is represented by two functionally active alleles (GSTM1-A and GSTM1-B) and by one null allele (GSTM1-0). ${ }^{16}$ The latter does not produce a protein product because of an expanded deletion. ${ }^{17}$ In most populations studied, 40$60 \%$ of subjects are GSTM1-0 homozygotes. These subjects have been shown to have increased risk of various cancers, ${ }^{18}{ }^{19}$ pulmonary emphysema, ${ }^{20}$ and chronic bronchitis. ${ }^{21}$ The homozygous null genotype has also been shown in one study to be associated with an earlier diagnosis of cystic fibrosis and death before the age of five years, suggesting that GSTM1-0 homozygosity in cystic fibrosis predisposes to more severe lung disease. ${ }^{22}$

In this study we have examined the effects of the -308 TNF- $\alpha$ polymorphism and the GSTM1 genotype on disease severity in 53 children with cystic fibrosis.

\section{Methods}

SUBJECTS

The study group consisted of 53 children (20 girls) with cystic fibrosis. All subjects attended the Oxford Cystic Fibrosis Clinical Centre. The diagnosis of cystic fibrosis was made on the basis of two positive sweat tests. In order to compare disease severity between different subjects without the influence of age, an obvious confounding factor, all clinical data on the children were collected during their eighth year of life. By this age most children are able to perform reliable forced expiratory manoeuvres for the purposes of lung function testing. Children were eligible for the study if clinical data, including lung function data, were available for their eighth year, and if DNA taken for CFTR genotyping had been stored.

CLINICAL DATA

Children at the Oxford Cystic Fibrosis Centre undergo a comprehensive review each year. As part of this review their weight is recorded and chest radiographs are scored using the Chrispin-Norman system. ${ }^{23}$ This scoring system gives a numerical score for the chest radiograph with a maximum of 38 indicating most severe disease. A Shwachman score of disease severity $^{24}$ is also calculated. The Shwachman score is based on assessments of general activity, nutritional status, physical examination and chest radiography, with a maximum of 100 indicating the mildest disease. Lung function (including forced expiratory volume in one second, $\mathrm{FEV}_{1}$ ) is measured using a Vitalograph spirometer (Vitalograph Ltd, Buckingham, UK). Sputum or cough swabs are also collected for microbiological testing. Children were recorded as being positive for Pseudomonas aeruginosa if this organism had been isolated on at least one occasion. These five clinical parameters were used as markers of disease severity.

GENOTYPE ANALYSIS

DNA samples stored at the time of CFTR genotyping were used for analysis. The presence of the -308 TNF- $\alpha$ polymorphism was detected using the method of Wilson and
Table 1 Overall clinical data for the 53 subjects in the study

\begin{tabular}{ll}
\hline $\mathrm{FEV}_{1}$ (\% predicted) & $83.4(78.5$ to 88.3$)$ \\
Weight $z$ score & $-0.59(-0.33$ to -0.85 \\
$\begin{array}{l}\text { Chrispin-Norman chest } \\
\quad \text { radiography score }\end{array}$ & $13.0(11.3$ to 14.7$)$ \\
Shwachman score & $80.5(77.8$ to 83.2$)$ \\
No. positive for $P$ aeruginosa & 17 of 53 \\
No. $\Delta$ F508 homozygous & 36 of 53 \\
\hline
\end{tabular}

Values are mean (95\% confidence interval).

$\mathrm{FEV}_{1}=$ forced expiratory volume in one second.

colleagues $^{9}$ with the adaptation of Huang and co-workers. ${ }^{14}$ Briefly, a 345 base pair (bp) fragment of DNA flanking the -308 polymorphic site was amplified using the polymerase chain reaction (PCR) from each sample of genomic DNA. The 3' primer used in the PCR reaction incorporates the -308 polymorphic site into an $\mathrm{NcoI}$ restriction site. If the TNF1 allele is present, the subsequent DNA fragment will be cut by $N c o$ I giving fragments of 325 and $20 \mathrm{bp}$. If the TNF2 allele is present (G to A transition) the NcoI site is destroyed and no cutting occurs. The fragments were resolved using a 2\% NuSieve GTG agarose gel (FMC BioProducts, Rockland, Maine, USA) and visualised by ethidium bromide staining.

GSTM1-0 homozygotes were also detected by PCR. ${ }^{25}$ GSTM1 specific primers were used to amplify a $271 \mathrm{bp}$ fragment of DNA. This fragment occurs within the region deleted in the GSTM1-0 allele and therefore in patients homozygous for this allele no amplification product was seen. Co-amplification of a $309 \mathrm{bp}$ fragment from exon 3 of the CFTR gene, using primers $3 \mathrm{i} 3$ (ATTCACCAGATTTCGTAGTC) and $3 i 5$ (CTTGGGTTAATCTCCTTGGA), was used as an internal standard for each PCR reaction. The fragments were resolved and visualised as described for the TNF- $\alpha$ analysis.

STATISTICAL ANALYSIS

Data for $\mathrm{FEV}_{1}$, chest radiographic score, weight $z$ score, and Schwachman score were normally distributed and comparisons between groups were made using the two tailed Student's $t$ test. Analysis of the presence or absence of Pseudomonas aeruginosa by the age of eight years was carried out using the $\chi^{2}$ test.

\section{Results}

Fifty three children were studied. The clinical details of the study population are shown in table 1. All children were assessed at the age of eight years in the Oxford Cystic Fibrosis Centre between 1984 and 1997. There was no difference in the distribution of date of review between any of the study groups; any effect of changes of treatment in more recent years thus affected all groups equally. Analyses of the TNF- $\alpha$ promoter polymorphism and the GSTM1 allele were successful in all subjects. The allele frequency for the TNF1 allele was 0.81 and for the TNF2 allele was $0.19 ; 49 \%$ of the study population were GSTM1 deficient (GSTM1-0/0).

Table 2 shows the recorded clinical parameters for the study group split according to the TNF- $\alpha-308$ polymorphism genotype. Only one subject was homozygous for the 
Table 2 Clinical markers of disease severity split by TNF-a genotype

\begin{tabular}{llllll}
\hline & $\begin{array}{l}\text { TNF1 } \\
(n=33)\end{array}$ & $\begin{array}{l}\text { TNF1/TNF2 } \\
(n=20)\end{array}$ & $\begin{array}{l}\text { Mean } \\
\text { difference }\end{array}$ & $95 \%$ CI & $p$ value \\
\hline${\text { Mean } \text { FEV }_{1} \text { (\% predicted) }}_{\text {Mean weight } z \text { score }}$ & 87.8 & 76.2 & 11.6 & 1.7 to 21.5 & 0.02 \\
Mean Chrispin-Norman chest radiographic score & 12.1 & -0.96 & 0.59 & 0.06 to 1.12 & 0.03 \\
Mean Shwachman score & 82.0 & 78.5 & 2.4 & -5.9 to 1.1 & 0.17 \\
No. positive for P aeruginosa & 10 & 7 & 3.8 & -1.7 to 9.4 & 0.17 \\
No. $\Delta$ F508 homozygous & 22 & 14 & & 0.72 \\
\hline
\end{tabular}

$\mathrm{FEV}_{1}=$ forced expiratory volume in one second.

Table 3 Clinical markers of disease severity split by GSTM1 genotype

\begin{tabular}{|c|c|c|c|c|c|}
\hline & $\begin{array}{l}\text { Normal } \\
(n=27)\end{array}$ & Null $(n=26)$ & $\begin{array}{l}\text { Mean } \\
\text { difference }\end{array}$ & $95 \% C I$ & $p$ value \\
\hline Mean $\mathrm{FEV}_{1}(\%$ predicted $)$ & 86.8 & 79.8 & 7.0 & -2.9 to 16.9 & 0.16 \\
\hline Mean weight $z$ score & -0.56 & -0.63 & 0.07 & -0.47 to 0.61 & 0.79 \\
\hline Mean Chrispin-Norman chest radiographic score & 11.0 & 15.0 & 4 & -7.3 to -0.8 & 0.02 \\
\hline Mean Shwachman score & 83.3 & 77.7 & 5.6 & 0.4 to 10.9 & 0.04 \\
\hline No. positive for $P$ aeruginosa & 6 & 11 & & & 0.12 \\
\hline No. $\Delta$ F508 homozygous & 17 & 19 & & & 0.43 \\
\hline
\end{tabular}

$\mathrm{FEV}_{1}=$ forced expiratory volume in one second.

TNF2 allele and for the purposes of analysis this subject has been included in the TNF1/ TNF2 heterozygous group. For each of the clinical markers of disease severity the presence of the TNF2 allele tended to be associated with more severe disease. The percentage predicted $\mathrm{FEV}_{1}$ in the TNF1/TNF2 group $(76 \%)$ was significantly lower than that for the TNF1 group $(88 \%, p=0.02)$. Weight $z$ score was also significantly lower in the TNF1/TNF2 group $(-0.96)$ than in the TNF1 group $(-0.37, \mathrm{p}=$ 0.03 )

Table 3 shows the recorded clinical parameters for the study group split according to GSTM1 status. For each of the clinical markers of disease severity the patients homozygous for the null allele tended to have more severe disease. Both the chest radiographic score and the Shwachman score were significantly worse in the GSTM1-0/0 group.

The proportion of subjects homozygous for the $\Delta$ F508 mutation was the same in all study groups. A small number of missense mutations have been shown to be associated with residual CFTR function and a mild clinical phenotype. ${ }^{26}$ None of the patients in the study group carried any of these defined mutations. When the subjects were classified according to whether they were $\Delta \mathrm{F} 508$ homozygous or $\Delta \mathrm{F} 508$ compound heterozygous no effect on disease severity was seen (data not shown). All but one of the study subjects were pancreatic insufficient.

\section{Discussion}

Doctors who care for children and adults with cystic fibrosis have long been aware that there is likely to be genetic variability in their patients which could explain why some patients seem to do considerably better than others. Some of this clinical heterogeneity can be explained by the type of CFTR mutations present. ${ }^{12728}$ However, given that there is clearly variability in disease severity, even amongst those patients who are homozygous for the $\Delta \mathrm{F} 508$ mutation, it seems likely that other factors are also important.

A previous study which has addressed this problem examined the effects of variation in alpha $a_{1}$-antitrypsin $\left(\alpha_{1}-\mathrm{AT}\right)$ allotypes on cystic fibrosis phenotype. ${ }^{29}$ This study showed a significant association between the $\mathrm{S}$ and $\mathrm{Z}$ $\alpha_{1}$-AT mutants and earlier onset of pulmonary colonisation with $P$ aeruginosa in patients with cystic fibrosis. The effect was small and there was no apparent effect on lung function. Nevertheless, this study suggested that nonCFTR genetic factors which influence cystic fibrosis phenotype could be identified.

In this study we have examined the effect of genetic variability in two genes, $\mathrm{TNF}-\alpha$ and GSTM1, which were predicted to be involved in the pathogenesis of cystic fibrosis. We have shown that the TNF2 allele and the null GSTM1 homozygous state are positively associated with markers of disease severity. The study was low powered to detect small effects and it is possible that some measures of disease severity which only tended to be worse in these groups of patients would be shown to be significantly different by larger studies.

The TNF2 allele was present in this study at a frequency of 0.19 . This is similar to that found in other studies in Caucasian populations..$^{3031}$ It is possible that the observed effects of the presence of the TNF2 allele result not from alteration of TNF- $\alpha$ production but rather because of linkage of TNF2 to nearby functionally unrelated genes. The TNF- $\alpha$ gene is located within the class III region of the major histocompatibility complex. The increased frequency of the TNF2 allele in patients with systemic lupus erythematosus ${ }^{32}$ and in patients with insulindependent diabetes mellitus ${ }^{31}$ has been shown to be dependent on the linkage disequilibrium between TNF- $\alpha$ and HLA-DR3. McGuire and colleagues $^{12}$ were, however, able to show that the effects of the TNF2 allele in cerebral malaria were independent of linkage to HLA genes. In this study we have not addressed the question of linkage disequilibrium with other genes. However, the central role of TNF- $\alpha$ in regulating inflammatory responses, and the correlation between TNF- $\alpha$ levels and cystic fibrosis disease severity, ${ }^{8}$ suggests that the association between the TNF2 allele and the 
more severe disease found in this study is due to effects on $\mathrm{TNF}-\alpha$ production.

The effects of the GSTM1 null allele are easier to interpret. This allele produces no functional protein, and the correlation between the null allele detected by the PCR method used in this study and absent GSTM1 enzyme activity has been shown by others. ${ }^{22}$ The GST multigene family of detoxifying enzymes is involved in protecting several tissue types from oxidative damage, as shown by the increased risk of subjects homozygous for the GSTM1 null allele for a number of different cancers as well as pulmonary emphysema and bronchitis. ${ }^{18-20}$ The usual mechanism proposed for the lung disease in these studies is reduced ability of GSTM1-0/0 subjects to deal with the oxidants in cigarette smoke and other inhaled or ingested toxins. In the cystic fibrosis lung there is now good evidence that high levels of oxidant stress are present from a very early age, ${ }^{5}$ in this case probably as a result of the release of reactive oxygen species by airway neutrophils. Levels of products of oxidant metabolism have been correlated with lung function in patients with cystic fibrosis. ${ }^{4}$ Increased levels of oxidant stress are exacerbated in patients with cystic fibrosis by reduced intake of dietary antioxidants. ${ }^{33}$ We suggest that the association between the GSTM1-0/0 genotype and cystic fibrosis disease severity seen in this study may be due to reduced ability to deal with oxidant stress, particularly within the lung. Pseudomonas aeruginosa was isolated from the sputum or a cough swab in $42 \%(11 / 26)$ of the GSTM1 null group compared with only $22 \%(6 / 27)$ of the GSTM1 normal group. Although this difference was not statistically significant, possibly due to the low power of the study, it does suggest another potential mechanism by which GSTM1 status could affect disease severity.

In conclusion, we have shown that two independent genetic variants can influence disease severity in patients with cystic fibrosis. As would be expected, the effects of these factors within individual patients are small. Nevertheless, group comparisons-for example, for $\mathrm{FEV}_{1}$ which showed changes of more than $10 \%$ - suggest that these effects may be clinically important. This study supports the contention that the pulmonary inflammatory response is excessive and damages the host. It is possible that identification of further genetic modifiers will not only increase our understanding of the pathogenesis of cystic fibrosis, but also allow identification of those patients who would most benefit from early intensive treatment. JH was supported by an Advanced Training Fellowship from the
Wellcome Trust, UK. The Oxford Cystic Fibrosis Centre is supported by the Cystic Fibrosis Trust. The authors thank Dr Ann Harris for her help and support.

1 Kubesch P, Dörk T, Wulbrand U, et al. Genetic determinants of airways colonisation with Pseudomonas aeruginosa nants of airways colonisation with Pseudo

2 Lester LA, Kraut J, Lloyd-Still J, et al. Delta-F508 genotype does not predict disease severity in an ethnically diverse cystic fibrosis population. Pediatrics 1994;93:114-8.

3 Rozmahel R, Wilschanski M, Matin A, et al. Modulation of disease severity in cystic fibrosis transmembrane conduct- ance regulator deficient mice by a secondary genetic factor. Nat Genet 1996;12:280-7.

4 Brown RK, Wyatt H, Price JF, et al. Pulmonary dysfunction in cystic fibrosis is associated with oxidative stress. Eur Respir F 1996;9:334-9.

5 Hull J, Vervaart P, Grimwood K, et al. Pulmonary oxidative stress response in young children with cystic fibrosis. Tho$\operatorname{rax}$ 1997;52:557-60.

6 O'Connor C M, Gaffney K, Keane J, et al. Alpha 1-proteinase inhibitor elastase activity and lung disease 1665-70.

7 Bonfield TL, Pansuka JR, Konstan MW, et al. Inflammatory cytokines in cystic fibrosis lungs. Am $\mathcal{F}$ Respir Crit Care Med 1995;152:2111-8.

8 Greally P, Hussein MJ, Cook AJ, et al. Sputum tumour necrosis factor-alpha and leukotriene concentrations in necrosis factor-alpha and leukotriene conce

9 Wilson AG, di Giovine FS, Blakemore AIF, et al. Single base polymorphism in the human tumour necrosis factor alpha (TNF- $\alpha$ ) gene detectable by NcoI restriction of PCR product. Hum Mol Genet 1992;1:353.

10 Kroeger KM, Carville KS, Abraham LJ. The -308 tumor necrosis factor-alpha promoter polymorphism effects transcription. Mol Immunol 1997;34:391-9.

11 Wilson AG, Symons JA, McDowell TL, et al. Effects of a tumour necrosis factor $(\mathrm{TNF} \alpha)$ promoter base transition on transcriptional activity. Br f Rheumatol 1994;33(Suppl 1):89.

12 McGuire W, Hill AVS, Allsopp CE, et al. Variation in the TNF- $\alpha$ promoter region associated with susceptibility to cerebral malaria. Nature 1994;371:508-11.

13 Messer G, Kick G, Ranki A, et al. Polymorphism of the tumor necrosis factor genes in patients with dermatitis herpetiformis. Dermatology 1994;189(Suppl 1):135-7.

14 Huang S-L, Su C-H, Chang S-C. Tumor necrosis factor- $\alpha$ gene polymorphism in chronic bronchitis. Am $\mathcal{F}$ Respir Crit Care Med 1997;156:1436-9.

15 Wilkinson J, Clapper ML. Detoxification enzymes and chemoprevention. Proc Soc Exp Biol Med 1997;216:192-200.

16 Groppi A, Coutelle C, Fleury B, et al. Glutathione $\mathrm{S}$-transferase class $\mathrm{mu}$ in French alcoholic cirrhotic patients. Hum Genet 1991;87:628-30.

17 Seidegard J, Vorachek WR, Pearson WR. Hereditary differences in the expression of the human glutathione transferase active on trans-stilbene are due to a gene deletion. Proc Nat Acad Sci USA 1988;85:7293-7.

18 Heagerty AHM, Fitzgerald D, Smith A, et al. Glutathione Heagerty AHM, Fitzgerald D, Smith A, et al. Glutathione
S-transferase GSTM1 phenotypes and protection against cutaneous tumours. Lancet 1994;343:266-7.

19 Strange RC, Matharoo B, Faulder GC, et al. The human glutathione S-transferases: a case control study of the incidence of the GSTM1 0 phenotype in patients with adenocarcinoma. Carcinogensis 1991;12:25-8.

20 Harrison DJ, Cantlay AM, Rae F, et al. Frequency of glutathione S-transferase M1 deletion in smokers with emphysema and lung cancer. Hum Exp Toxicol 1997;16: 356-60.

21 Baranova H, Perriot J, Albuisson E, et al. Peculiarities of the GSTM1 0/0 genotype in French heavy smokers with various types of chronic bronchitis. Hum Genet 1997;99:822-6.

22 Baranov VS, Ivashenko T, Bakay B, et al. Proportion of the GSTM1 $0 / 0$ genotype in some Slavic populations and its correlation with cystic fibrosis and other multifactorial diseases. Hum Genet 1996;97:517-20.

23 Chrispin AR, Norman AP. The systemic evaluation of the chest radiograph with cystic fibrosis. Pediatr Radiol 1974;2: 101-5.

24 Shwachman H, Kulczycki LL. Long term study of one hundred and five patients with cystic fibrosis. Am F Dis Child 1958;96:6-15.

25 Brockmöller J, Kerb R, Drakoulis N, et al. Glutathione $\mathrm{S}$-transferase M1 and its variants A and B as host factors of ladder cancer susceptibility: a case control study. Cancer Res 1994;54:4103-11.

26 Zielenski J, Tsui L-C. Cystic fibrosis: genotype and phenotypic variations. Annu Rev Genet 1995;29:777-807

27 Johansen HK, Nir M, Hoiby N, et al. Severity of cystic fibrosis in patients homozygous and heterozygous for $\Delta$ F508 mutation. Lancet 1991;337:631-4.

28 Kerem E, Corey M, Kerem B, et al. The relation between genotype and phenotype in cystic fibrosis- analysis of the genotype and phenotype in cystic fibrosis- analysis of the
most common mutation $\left(\Delta \mathrm{F}_{508}\right) . N$ Engl f Med 1990;323: most comm

29 Döring G, Krolgh-Johansen H, Weidinger S, et al. Allotypes of alpha ${ }_{1}$-antitrypsin in patients with cystic fibrosis, homozygous and heterozygous for deltaF508. Pediatr Pulmonol 1994;18:3-7.

30 Fernandez-Real JM, Gutierrez C, Ricart W, et al. The TNFalpha gene NcoI polymorphism influences the relationship among insulin resistance, percent body fat, and increased serum leptin levels. Diabetes 1997;46:1468-72.

31 Deng GY, Maclaren NK, Huang HS, et al. No primary association between the -308 polymorphism in the tumor necrosis alpha promoter region and insulin-dependent diabetes mellitus. Hum Immunol 1996;45:137-42.

32 Rudwaleit $M$, Tikly $M$, Khamashta $M$, et al. Interethnic differences in the association of tumor necrosis factor polymorphisms with systemic lupus erythematosus. $f$ polymorphisms with systemi

33 Portal BC, Richard M-J, Faure R, et al. Altered antioxidant status and increased lipid peroxidation in children with cystic fibrosis. Am f Clin Nutr 1995;61:843-7. 